Christine Dimroth, MPI für Psycholinguistik,

Nijmegen

\title{
Stepping stones and stumbling blocks. Why negation accelerates and additive particles delay the acquisition of finiteness in German ${ }^{1}$
}

\section{Introduction}

This paper deals with a crucial step in the early development of German as a first or a second language. First and (untutored) second language learners are known to develop early learner varieties that lack productive inflectional morphology as well as functional elements (Jordens \& Dimroth 2006, Klein \& Perdue 1997). The question of how learners move from this lexically-based utterance structure to more target-like organization of sentence grammar is crucial for theories of language acquisition.

When learners first start to combine words into two- or multi-word utterances, there are no purely grammatical markers yet. However, some elements that differ from the prevalent group of lexical expressions are typically attested. Such elements are not referring to anything, but rather specifying the relation between other pieces of information given in the utterance, or between information in the utterance and the (non)-verbal context. Several studies have found that for German, negative particles like nein ('no') and nicht ('not') and the additive particle auch ('also') are among the first elements of this sort (Dimroth 2002, Nederstigt 2003, Penner, Tracy, and Weissenborn 2000, Winkler, this volume). It has also been suggested that utterances containing these expressions are somehow more advanced and can help the child and the untutored L2 learner to develop from the lexical structure of their early utterances towards a more target-like finite utterance structure (Dimroth et al. 2003, Penner et al. 2000). But although nicht and auch have broadly comparable syntactic properties in German, they do not develop on a par in further stages of language acquisition.

The paper addresses the question of how these devices are integrated into elementary learner utterances, in particular when they are first combined with verb-like words, and what the consequences are for utterance organization. The role of information structure is invoked in order to explain why these particles do not develop in a parallel way.

This paper is organized as follows: Section 2 presents some basic observations concerning early learner utterances (L1 and L2) containing negation or the particle auch. Section 3 summarizes different accounts that have been proposed for the structure underlying these simple learner utterances. In Section 4 it is shown that these particles show a very different behaviour when finiteness actually emerges in learner languages.

\footnotetext{
${ }^{1}$ I wish to thank Sandra Benazzo, Wolfgang Klein, Leah Roberts, Sarah Schimke, and Josje Verhagen for helpful comments on an earlier version of this paper.

2 According to a different view such elements are there but not always visible on the surface (Prévost \& White 2000).
} 
Section 5 examines the information structure of utterances containing the particles in adult native speakers. The question of whether similar information structural constraints are at work in learner language and could possibly explain the differences attested between auch and nicht are addressed in Section 6, and Section 7 contains a discussion of the findings.

\section{Basic observations: word order in non-finite learner utterances}

The study of negation in the first and second language acquisition of German has a much longer tradition (Becker 2005, Clahsen 1988, Dietrich \& Grommes 1998, Meisel 1997, Verrips \& Weissenborn 1992, Wode 1977) than the study of additive particles like auch (Benazzo 2003, Berger et al. 2007, Dimroth 2002, Hulk 2003, Nederstigt 2003, Penner et al. 2000, Schimke, Verhagen, and Dimroth 2008, Tracy 2002, Winkler, this volume).

For L1 development it has been shown that the negation particle nein is typically acquired earlier than the particle nicht (see Wode 1977, Clahsen, 1988). In the target language nein is used anaphorically and often holistically, i.e. what is negated is not part of the utterance containing the particle. nicht on the other hand is used for non-anaphoric negation, i.e. integrated in an utterance and affecting (part of) it with its negative meaning. According to Wode (1977) however, nein can also be used non-anaphorically in early child language. ${ }^{3}$ In the early stages of L2 acquisition of German a wider variety of negation particles is used. As early as in the so-called pre-basic variety ${ }^{4}$, Dietrich \& Grommes (1998) attest kein (negative determiner), niks (nothing), nein (no), nee (colloquial version of nein), and $\operatorname{nicht}(t)$ (not) which often occur interchangeably.

In the current study, we are not so very much interested in the type of negative particle, but in the way in which it is integrated in learner's utterances. With respect to both negation (be it spelled out as nicht, nein or niks) as well as the particle auch, I am not interested in anaphoric or holistic use as sentence equivalents, but in the structure of utterances in which these elements occur with at least one other word that is affected by their additive or negative meaning. In the remainder of this paper nicht is going to be used as a cover-term for the other negative items occurring with a similar function.

The particles auch and nicht are already found in the earliest two word utterances in child German and also appear very early in the data of untutored learners of German as an L2. Compare the following example from L1 German (from Nederstigt 2003):

(1) Caroline 1;10

Mother: nachher müssen wir mal die Großmutter anrufen? later we should call grandma

Child: Großvater auch

Grandpa too

At this point in development, the learners' inventory mainly consists of lexical elements, or "content signs" (van Kampen 2005) that can fulfil referring or predicating function. Elements like auch and nicht are not used for reference or predication but rather to modify

\footnotetext{
${ }^{3}$ See example (4) below.

${ }^{4}$ For a definition, see Perdue 1996.
} 
one of these operations. This is typically done in contexts that help identify part of the content the child is talking about and often involves the implicit expression of the child's wishes or requests (see (1) above). Due to this function, these particles (amongst other elements) have been called illocutionary operators (Hulk \& van der Linden 2005) or pragmatic operators (van Kampen 2005). In an early attempt to characterize their function as anchor points of an utterance Braine (1963) referred to these (and other) elements as pivots. There is no full agreement in the literature about the items that belong to this class of first operator-like elements. ${ }^{5}$

Authors studying the structure of early two-word combinations stress that these operator-type elements do not yet (or only partly) have the functional properties of their adult language counterparts. Jordens \& Dimroth (2006) therefore speak about lexical linking elements, Hulk \& van der Linden (2005) about pseudo functional operators, and Powers (2001) calls them semi-lexical heads. In the following section we look more closely at the focus particle auch and the negative particle nicht and the way they combine with referring and predicating elements.

In L1 data from the two-word stage, both word order possibilities are attested, i.e. the particles can precede or follow the 'other' word. Consider the following examples for auch and nicht in early two-word combinations from L1 ${ }^{6}$ :

(2) Julia, 1;07

word order:

J. puts blocks in a box darein

there-in

picking up another block auch darein auch $\mathrm{x}$

also there-in

(3) Julia, 1;11

$J$. puts toys in a box

einräum

put-in

placing goat in the box

ziege auch

$\mathrm{x}$ auch

goat also

(4) Inga, 1;11;2

nein sauber

nicht $\mathrm{x}$

no clean

(5) Juwal, 1;03

ditsinei $\mathrm{x}$ nicht

cookies no

The structure of two-word utterances has been investigated more intensively in L1 than in L2 acquisition - probably because there is no clear stage in second language acquisition at which the maximal length of utterances corresponds to two words. Rather, rudimentary utterances in adult language are often difficult to distinguish from ellipsis (relying on native speaker scaffolding, see Andorno 2008, and Perdue 1996). As in L1 acquisition, both word orders are attested in early L2 utterances. Evidence is presented in Dimroth (1998) for auch and Becker (2005) for nicht.

\footnotetext{
5 See the contributions to the volume "Semi-lexical Categories. The Function of Content Words and the Content of Function Words" (Corver \& van Riemsdijk (eds.) 2001).

${ }^{6}$ Examples (2), (3), (5) from Penner et al. 2000; (4) from Wode 1977.
} 
Interestingly, we do not seem to find the same flexibility in position when the particles show up in combination with verb-like words, that are, at that stage, not yet marked for finiteness. In contrast, the initial order seems to be fixed, as auch and nicht always precede the verbal element, as in examples (6) and (7) below ${ }^{7}$.

(6) Caroline, 1;09

word order

Mother:

was kleines bauen?

build something little?

Caroline: auch baun

auch $\mathrm{V}$

also build

(7) Juwal, 1;08

nei faffe

$\operatorname{nicht} \mathrm{V}$

no sleep

Early second language learners also tend to put these particles in a position preceding the non-finite verb (see e.g. Dimroth 2002 and 2008, Meisel 1997, Schimke et al. 2008, Verhagen 2005).

\section{Different accounts}

The observation that particles like auch and nicht can in principle appear on both sides of content words involved in the construction of early two-word utterances has led to different accounts. Powers (2001) refers to auch as a "flipping pivot". This terminology goes back to Braine's (1963) proposal, in which two classes of pivot words were originally distinguished on the basis of their position in such two-word utterances. "While Braine defined two classes of pivots, initial and final, these classes were not exclusive: lexical items like auch (...) seem to belong to both classes." (Powers 2001: 112).

Powers assumes that, in contrast to adult functional heads, children's semi-lexical heads (like auch and nicht) do not occur in fixed positions relative to their complements. In order to ensure that they always project, semi-lexical heads must be represented as heads in the lexicon. Expanded representations with an empty position for an open class element (like the ones given in Figure 1) are also assumed to be stored lexically. The empty position can be situated on either side of the particle (as in a) or b) below).

Figure 1 (adapted from Powers 2001)

a)

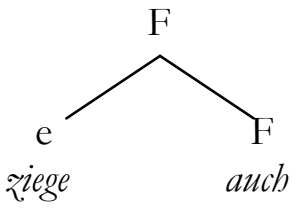

b)

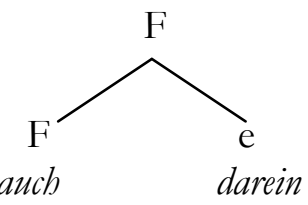

The 'flipping pivots' problem only arises under Braine's (1963) assumption that pivot elements fall into two distinct classes, that are associated with either the initial $\left(\mathrm{P}_{1-}\right)$ or the final $\left(\_\mathrm{P}_{2}\right)$ position in two-word constructions of the type illustrated in examples (1)(5). In order to avoid two different entries for a particle like auch (auch $1_{-}$and _auch ${ }_{2}$ )

\footnotetext{
${ }^{7}$ Example (6) from Nederstigt 2003; (7) from Penner et al. 2000.
} 
Powers (2001) proposes a third class of pivot words that can appear as $\mathrm{P}_{1}$ or $\mathrm{P}_{2}$. She does not assign systematic meaning differences to the two positions.

Learner utterances in which the particles precede a verb as in the following example (from Penner et al., 2000) have given rise to different analyses.

(8) Florian, 2;08 (lies down and places toy man next to himself)

mann auch schlafte

man also sleep

Penner et al. (2000) as well as Tracy (2002) consider these particles as syntactic precursors of finiteness and claim that auch and nicht project their own roots and take VP as their complement. Similar to the 'flipping pivot' analysis presented above, the particles are the head of a Focus-Particle Phrase (FP). This additional layer is seen as a trigger for early scrambling, as these authors observe that as soon as these particle-verbcombinations co-occur with noun phrases (as in (8) above), "constraints on scrambling are observed, i.e. (a) subjects raise; (b) definite objects may or may not raise, and (c) indefinite objects do not raise." (Penner et al., 2000; 138). The corresponding structure is depicted in Figure 2.

Figure 2 (from Penner et al., 2000)

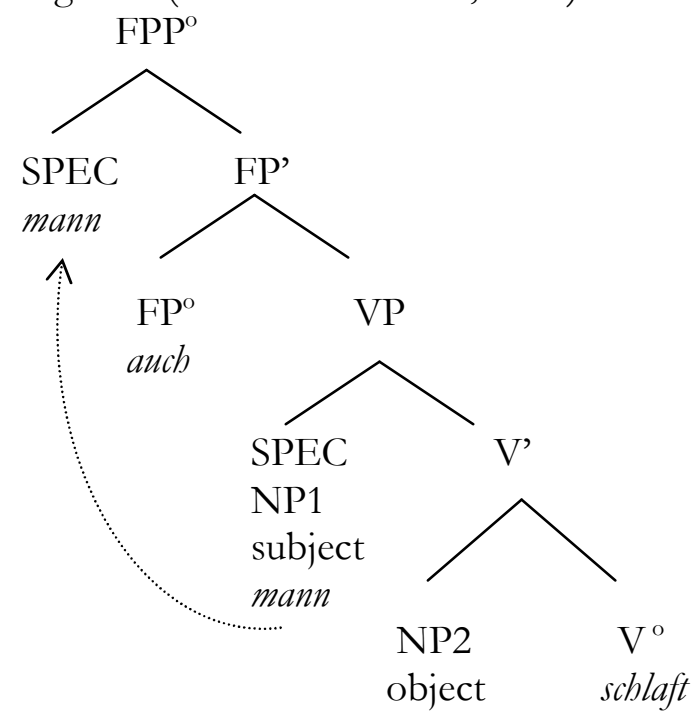

Penner et al. (2000) conclude that these particles act like perfect bootstraps, helping the child to construct additional structural layers beyond VP. In the next developmental step then yet another structural layer is created to which the verb can raise. The same syntactic structure and the same bootstrapping function is proposed for negation with nicht, even though it is shown that auch is acquired earlier than nicht, presumably because the former occurs in only one form and is therefore more accessible in the input. Once discovered, "the negation marker is assimilated to the scheme originally yielded by auch. In analogy with the auch-headed Focus-Particle Phrase, the negation marker is initially analyzed as a head, projecting a complement slot for the VP and a SPEC position.” (p. 155).

Dimroth et al. (2003) and Jordens \& Dimroth (2006) have also investigated the role of such elements (and their Dutch equivalents) in early phases of first and second language acquisition. They claim that these particles are best analysed as functional rather than 
structural precursors of finiteness. When they first appear, learner utterances do not yet show a hierarchical organization like the one displayed in Figure 2. Rather, word order at that point in development (called "Conceptual Ordering Stage") is determined by principles of information structure. Utterances consist of three structural positions, each of which goes with a particular informational function. Children and adult L2 learners put topic information (i.e. expressions identifying the situation they are talking about (Klein, 2008)) in initial position. The final position is filled by expressions functioning as the predicate of their utterances, rendering what the speakers want to say about the utterance's topic. Thus, the predicate functions as comment. These predicates can (but need not) contain verbs. Between the topic and the predicate so-called "lexical linking devices" can occur. Jordens \& Dimroth (2006) identify a closed class of such linking items (including nicht and auch and their Dutch counterparts) which are used to qualify the relation between the predicate and the topic.

If no such linking device is present, the utterance expresses the default relation of assertion (see (9a) and (10a) below). Word order is not seen as a result of scrambling, but determined by a sequential ordering of positions related to information structure. Syntactically, the constituents are adjuncts.

Figure 3 (adapted from Dimroth et al. 2003); L2 utterances from Janka (L1 = Polish; PMoLL Corpus, $\mathrm{MPI}^{8}$ ) and Angelina (L1 = Italian, ESF-Corpus, MPI):

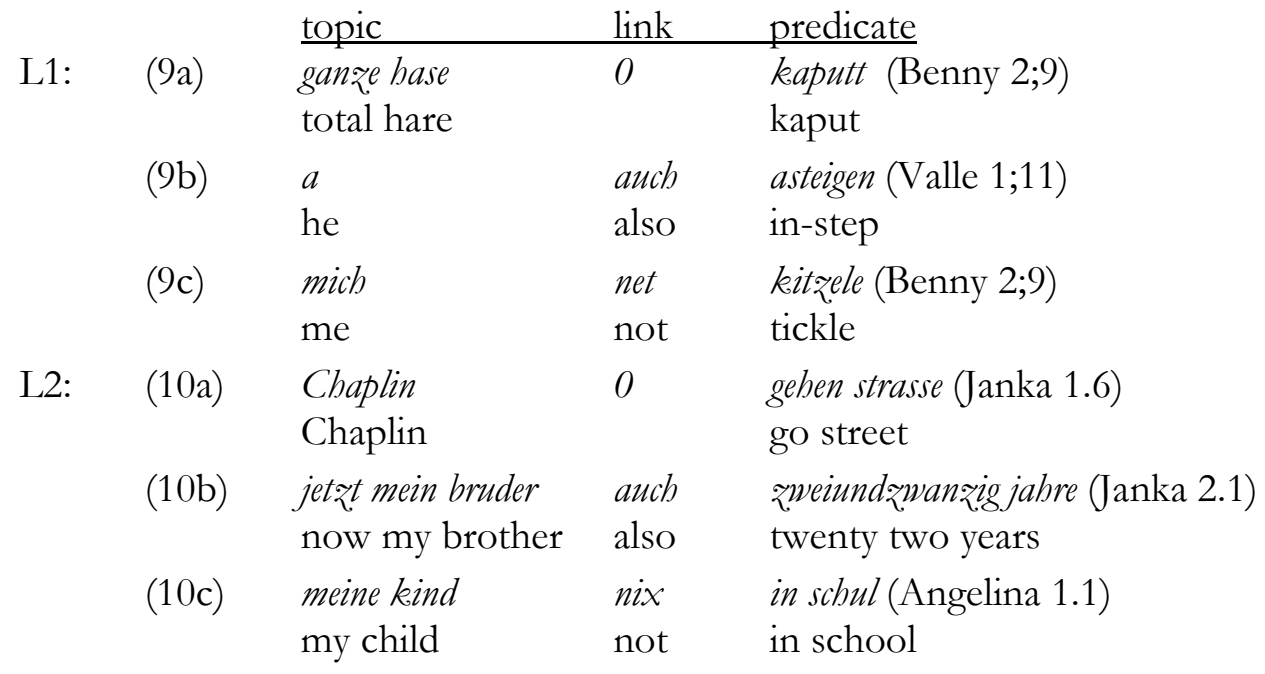

In more developed learner varieties and in the target language it is one of the functions of finiteness to express that an utterance makes an assertion about its topic (Klein, 2006). The lexical linking words from the Conceptual Ordering Stage illustrated above are considered formal precursors of finiteness only in the sense that they occupy the position between topic and predicate that is later filled by auxiliaries - the first elements to be productive carriers of features of finiteness (Jordens \& Dimroth, 2006). The particles are seen as functional precursors since they affect the relation between topic and predicate as assertion marking through finiteness does.

\footnotetext{
${ }^{8}$ The L2 data used in this paper can be found under http://corpus1.mpi.nl. If not indicated otherwise, the examples from L1 are quoted from other papers.
} 
While both approaches share the idea that these particles are precursors of finiteness, the actual spell out differs. Penner et al. (2000) and Tracy (2002) assume that from early on the particles lead to the creation of new layers of syntactic structure, whereas Dimroth at al. (2003) and Jordens \& Dimroth (2006) assume a more limited contribution to structure building, through the occupation of a slot following the topic constituent that is later taken over by the first functional carriers of finiteness, namely auxiliary verbs. In addition, they argue that it is the function of the early particles to lexically specify the relation between predicate and topic, i.e. for example to express that some predicate does or does not hold for a given topic - a function that is later taken over by morphosyntactic finiteness marking.

Whatever the reason for considering such particles as precursors of finiteness - neither of the proposals makes explicit predictions about what happens when finiteness comes into play. Both claim that these particles promote the development of additional structure in the sense that this structure can be build by further developing the utterance pattern that was used with the particles. But what is expected for utterances that actually contain the relevant particles? Is finiteness marking in utterances that at the same time contain such precursor items different from finiteness marking in utterances that do not? And if so, does the presence of the precursor items push upcoming finiteness marking in such utterances or does it actually hamper it? The former scenario suggests itself because precursors are normally considered to be stepping stones and not stumbling blocks, but the latter is also not implausible. Instead of an alternative (and maybe functionally related) filling for an available structure, having both the particle and finiteness marking in the same utterance somehow implies structure building on top of the existing structure and coding of a function in addition to the functionally similar existing one (which learners might find redundant).

Neither of the two approaches makes clear predictions about how particles and finiteness interact, but both seem to tacitly assume that auch and nicht behave similarly in that respect. As shall be shown in the following section, however, this is not the case. The particles auch and nicht behave very differently as soon as young children and adult L2 learners start marking their utterances for finiteness in a more target like way.

\section{Differences between auch and nicht with emerging finiteness}

Let us first have a look at the distribution of morpho-syntactic markings of finiteness (mainly spelled out as subject-verb agreement and verb raising) in negated vs. nonnegated utterances. It turns out that in first as well as second language acquisition finiteness is marked earlier in negated than in non-negated utterances. Compare the following two concluding statements:

L1: "The results show that (...) in German L1 the marking of finiteness is realized significantly more often in negated contexts" (Winkler 2006: 106).

L2: "Die Verteilung zeigt deutlich, daß die Finitheitsmarkierung durch das Vorhandensein von Negation im Satz begünstigt wird..." (Dietrich \& Grommes, 1998: 200) ["The distribution clearly indicates that finiteness marking is promoted by the presence of negation in the sentence...”] 
Winkler (2006) presents the longitudinal data from the Caroline Corpus summarized in Table (1).

Table (1): Negation and finiteness in L1 acquisition

\begin{tabular}{|l|l|l|}
\hline \multirow{2}{*}{ Age } & \multicolumn{2}{|l|}{ morpho-syntactic finiteness marking } \\
\cline { 2 - 3 } & nicht-utterances & other utterances \\
\hline $1 ; 11-2 ; 00$ & $50,0 \%$ & $7,2 \%$ \\
\hline $2 ; 01$ & $72,0 \%$ & $18,5 \%$ \\
\hline $2 ; 02$ & $70,4 \%$ & $41,8 \%$ \\
\hline $2 ; 03$ (till 2;03.10) & $88,9 \%$ & $82,8 \%$ \\
\hline
\end{tabular}

As soon as L2 learners start to use finiteness marking in a more systematic way, we note the same pattern as in L1 acquisition. ${ }^{9}$ Finiteness is marked more frequently in negated utterances than in non-negated utterances produced at the same time. Table 2 summarizes longitudinal data from a study by Dietrich \& Grommes (1998) involving three untutored adult L2 learners of German (L1 = Italian) from the ESF Corpus.

Table (2): Negation and finiteness in L2 acquisition

\begin{tabular}{|l|l|l|l|}
\hline stage & \multirow{2}{*}{ Learner } & \multicolumn{2}{|l|}{ morpho-syntactic finiteness marking } \\
\cline { 3 - 4 } & & nicht-utterances & other utterances \\
\hline stage 1 & Angelina & $62,5 \%$ & $19,3 \%$ \\
\hline stage 2 & Tino & $100 \%$ & $42 \%$ \\
& Marcello & $63,6 \%$ & $59,3 \%$ \\
\hline \multirow{2}{*}{ stage 3 3} & Tino & $100 \%$ & $87,1 \%$ \\
& Marcello & $88,9 \%$ & $76,6 \%$ \\
\hline stage 4 & Marcello & $100 \%$ & $97,7 \%$ \\
\hline
\end{tabular}

${ }^{9}$ At first sight the developmental pattern looks a bit more confusing in L2. In very early varieties negation and finiteness markers tend to occur in complementary distribution (Becker, 2005; Giuliano, 2003). This looks like counter evidence to the claim that negative utterances are more advanced than affirmative ones with respect to finiteness marking, and is illustrated in the example from the Polish Lerner Janka (P-MoLL Corpus, MPI) below:

leute in kudamm spazieren

people in kudamm go-for-a-walk

das is gut

that is good

und leute nich zubause

and people not at-home'

und mädchen nich kochen

and girls not cook

aber *teatr*, kino

but theatre, cinema

das is schön

that is nice

The question arises, however, as to whether one can really say that finiteness is emerging at that stage in development, given that only finiteness marker attested here is the copula in rather formulaic expressions of the form 'das is...' ('that is...') and lexical verbs are absent or only show up in non-finite forms. 
These findings are in accordance with the idea that negative particles facilitate the acquisition of finiteness. The situation is different for the particle auch. Utterances containing this particle are apparently not developing in the same way when finiteness marking becomes more productive. Compare the following summarizing statements.

L1: "Even after V2 has become productive, utterances with auch often drop the verb, the verb is non-finite, or it does not raise" (Penner et al. 2000: 138).

L2: "Dans nos données, la finitude était plus souvent marquée dans les énoncés sans particules que dans les énoncés avec particules" (Schimke et al. 2008: \#). ["In our data finiteness was more often marked in utterances without particles than in utterances containing particles" $]^{10}$

The claim by Penner et al. (2000) is based on child utterances like the ones in the following example.

(11) Julia 2;4 (talking about a bee sting)

de hat ein ein biene reinstich

there has a bee pricked

Julia Florian auch in nase stechen $\backslash$

Julia florian also in nose prick-INF

In (11) an utterance containing no particle but a finite auxiliary is immediately followed by one containing the particle auch and the same lexical verb (reinstechen, 'sting') in non finite form (with infinitival suffix and in end position).

Even when verbs are morphologically finite, auch can be a stumbling block for the realization of verb raising. Penner et al. (2000) quote the child utterance in (12) as an example for auch occuring with a morphologically finite but non-raised modal verb and conclude "...even after V2 effects are productive in principle, structures with auch still behave conservatively" (p. 136). ${ }^{11}$

Benny $(2 ; 2)$

ich auch will fee

I also want coffee

Penner et al. (2000) present quantitative evidence from two longitudinal child language corpora for their claim that utterances containing auch actually lag behind with respect to finiteness marking. In the Swiss German Corpus from Juwal up to age 2;4 only 11\% of all utterances containing auch (total $=80$ utterances) are marked for finiteness. Utterances without the particle auch show a much higher proportion of finiteness marking: between $1 ; 11$ and $2 ; 053 \%$ of all verbs are inflected, and at $2 ; 4$ already $80-90 \%$ of all verbal constructions are finite.

\footnotetext{
10 This statement summarizes results for the particles auch and wieder (again) and their Dutch counterparts, but Schimke et al. (2008) show that there also is a significant difference in finiteness marking for each particle alone.

${ }^{11}$ Compare similar examples in Winkler (this volume).
} 
On the basis of the data from the Simone Corpus a direct comparison between finiteness marking in utterances containing auch as opposed to nicht was carried out (Penner et al. 2000). The result is summarized in Table (3).

Table (3): Particles and finiteness in L1 acquisition (Simone Corpus) $)^{12}$

\begin{tabular}{|l|l|l|}
\hline \multirow{2}{*}{ age } & \multicolumn{2}{|l|}{ morpho-syntactic finiteness marking } \\
\cline { 2 - 3 } & auch utterances & nicht utterances \\
\hline $1 ; 10-2 ; 04$ & $41 \%$ & $65 \%$ \\
\hline
\end{tabular}

total $=144$ utterances

The tendency of auch to occur in non-finite utterances has also been observed in L2 data from German. The following examples from Dimroth (2002) illustrate the phenomenon. Learners tend to drop auxiliary verbs when auch is present (as in example (13) below), and series of utterances in which the same lexical verb occurs in its finite form without auch and in its non finite form when auch is present are equally attested (example 14).

Cevdet (L1 = Turkish, ESF Corpus, MPI)

die sind runnergefallen

they have fallen-down

und der mann auch runtagefallen

and the man also fallen-down

die mädchen und der chaplin sind aufgestanden

the girl and chaplin have gotten-up

und die polizei auch aufgestanden

and the police also gotten-up

(14) L2 learner rg13 (L1 = Russian, Additive-Story Corpus, MPI)

er sitzit und trinkt

he sit-3sg and drink-3sg

auch sitzen und/

also sit-inf and/

Schimke et al. (2008) confirme this observation on the basis of a larger data base. They tested 49 beginning Turkish learners of L2 German in an experimental study and found a significant difference between finiteness marking in utterances containing auch as compared to utterances without particles that were used in a similar context. A summary of their data is given in Table (4).

Table (4): auch and finiteness in L2 acquisition (cross-sectional data from 49 L2 learners)

\begin{tabular}{|l|l|}
\hline \multicolumn{2}{|l|}{ morpho-syntactic finiteness marking } \\
\hline auch-utterances & other utterances \\
\hline $46 \%$ & $63 \%$ \\
$(31 / 68)$ & $(47 / 75)$ \\
\hline
\end{tabular}

\footnotetext{
12 While Penner et al. (2000: 157) acknowledge that “...auch-utterances tend to occur more often as nonfinite than nicht-utterances", it is unclear why this observation does not seem to challenge their overall assumption that "utterances containing nicht are equally conservative" (p. 136).
} 
It seems, therefore, that auch is rather a stumbling block than a stepping stone for the acquisition of finiteness. This is confirmed, if we look at more advanced stages of L2 acquisition. When learners have developed a variety in which all utterances have a morphologically finite verb that is raised to V2, nicht is obligatorily post-finite (Dimroth, 2008; Verhagen, 2005), but auch still frequently occurs in pre-finite position. The utterances in (15) illustrate this point. Even finite verbs that raise over direct objects do not raise over auch. This is almost never the case with negation (compare the target like position of nicht in $15 \mathrm{~b}$ and $15 \mathrm{f})$.

(15) Child/adolescent L2 learners, (L1 = Russian; DaZ-AF Corpus, MPI)

a ich auch babe es gemacht (Das 31)

I also have it done

b ich auch wusst(e) das nich(t) (Das 45)

I also knew this not

c diese junge auch geht in elfte klasse (Das 55)

this boy also goes to $11^{\text {th }}$ grade

$\mathrm{d} A$. auch geht mit für schwimmen (Nas 05)

A. also goes with-us for swimming

e mama auch hat das (Nas 08)

mummy also has this

f mama auch weiss nicht, welches haus (Nas 13)

mummy also knows not, which house

$\mathrm{g}$ die auch baben ein haus (Nas 19)

they also have a house

h D. auch hat angst (Nas 22)

D. also is frightened

Schimke et al. (2008) show that this effect is independent of morphological finiteness (see Table 5 below). They compared lexical verbs with and without finite inflection (target like subject-verb agreement) in production data from 49 Turkish learners and found that finite verbs do not raise significantly more often across auch than non-finite verbs.

Table (5): position of auch in relation to morphologically finite and non-finite lexical verbs

\begin{tabular}{|l|c|c|}
\hline & preverbal & postverbal \\
\hline non-finite verbs & 23 & 2 \\
\hline finite verbs & 20 & 3 \\
\hline
\end{tabular}

In L2 acquisition auch is thus clearly a hindrance to verb raising. The evidence presented in this section indicates that L1 and L2 learners show a similar tendency during the acquisition of finiteness. Negated utterances are more advanced than affirmative utterances without particles, whereas utterances containing auch are less advanced.

Figure 4: frequency of finiteness marking in different utterance types

\section{utterances with nicht $<$ utterances without particles $<$ utterances with auch}

The syntactic as well as the more functional approach discussed in section 3 assume that the early utterances containing auch and nicht in L1 and L2 have the same structure. The 
syntactic approach (Penner et al. 2000) sees both particles as heads of a projection above VP whereas the functional approach (Jordens \& Dimroth 2006) sees both particles in a mediating position between the utterance's topic and the comment that is claimed to hold for that topic.

If however both these particles behave alike syntactically or information structurally and play a pioneering role for the acquisition of finiteness - why do they behave so differently as soon as finiteness comes into play? Jordens \& Dimroth (2006) do not address this question at all; Penner et al. (2000: 155) ask why finiteness marking in auch utterances lags behind utterances without particles. The answer is, however, more of a description than of an explanation: “...even in the period in which the inflected verb is regularly raised, auch constructions are preferably realized as infinitives. This trait can be accounted for if we assume that the underlying (...) configuration with a Focus Particle Phrase governing a VP tends to remain unchanged during early grammar" (Penner et al, 2000: 155).

There is, however, a crucial difference between the way in which auch and nicht are integrated in these early utterances when a second dimension of information structure is taken into account: the difference between given and new information. Before turning back to auch and nicht in learner language, let us first have a closer look at this dimension of information structure in the corresponding target language utterances.

\section{$5 \quad$ Nicht and auch in adult native German}

In his analysis of sentential negation in German, Klein (2007) distinguishes two main functions of negation. Independently of its position in a sentence, negation reverts the truth value of that sentence. The second function of negation is to indicate where the 'compatibility problem' is situated, i.e. which part of the negated sentence would have to be different in order to turn it into a true affirmative claim. It is only for this second function that the position of the negative particle in the sentence matters, and it matters in so far as the particle must precede the part of the sentence in which the sentence differs from its true counterpart. Consider the following example (from Klein 2007):

Maria ist zum ersten mal nicht gekommen.

Mary has for-the first time not come

Negation expresses that the corresponding sentence without the particle (Maria ist zum ersten mal gekommen) is false and the position of nicht indicates that the difference between (16) and a corresponding true sentence is to be found in the elements following negation, thus here gekommen, since there is only this one element. So in (16) it is undisputed that Mary did something for the first time. All that is negated is that the property that Mary had for the first time in this particular situation is 'coming'. If 'coming' were replaced by some predicative information different from it, the result could be a true statement.

Unfortunately, integration is not always as unequivocal as in example (16) above. Two additional problems make this simple analysis more complicated. The first one has to do with the particles being placed in a position where they precede more than just one constituent. Klein (2007) suggests that, depending on the distribution of new and given information in the part of the utterance following nicht, it is possible that only a set of the 
constituents in the particle's scope yield a compatibility problem with the sentence's positive counterpart. In the sentence in (17) it is unclear whether what is incompatible (and therefore felt to be negated) is the temporal adverbial zum ersten mal, or the property gekommen, or both.

\section{Maria ist nicht zum ersten mal gekommen. \\ Mary has not for-the first time come}

It is possible that only a set of the constituents following the particle expresses "different and incompatible" information. When uttered in a context in which it is clear that Mary came, the verb kommen is expressing given information and is therefore deaccented. This yields a reading in which it is not negated that Maria came, but only that this happened for the first time. When uttered in a context in which it is established that Mary, in the situation talked about, did something for the first time, then this is given information and deaccented. As a consequence what is "incompatible" and negated is only the property of coming.

The second complication does not have to do with the constituents following nicht, but with the ones preceding it. According to Klein (2007) the position of nicht helps to partition the sentence into two parts. In the part following the particle, the sentence is (at least partly, see above) incompatible with an affirmative counterpart, whereas the part preceding the particle is fully compatible. In other words, what is preceding the particle is not affected by negation. This non-negated element is often the topic of the utterance, as in the following example:

$$
\begin{aligned}
& \text { A: Was macht denn Maria? } \\
& \text { What about Mary? } \\
& \text { B: Keine Abnung. Sie war nicht hier. } \\
& \quad \text { No clue. She was not here. }
\end{aligned}
$$

This little dialog is about the topic Maria. The pronoun referring to this topic entity precedes the particle nicht in B's utterance and is unaffected by negation. I shall call this case the 'neutral topic case'. Things can be more complicated, however. Consider the Butterance in (19), which involves a special intonation pattern (raising accent on the bier, falling accent on nicht). ${ }^{13}$

$$
\begin{aligned}
& \text { A: Was macht denn Maria? } \\
& \text { What about Mary? } \\
& \text { B: Keine Ahnung. Hier war sie nicht. } \\
& \text { No clue. Here was she not. }
\end{aligned}
$$

In (19), speaker B makes a claim about a place, namely the one referred to by here and expresses that this was not the place where Mary was. In this case, the topic of the assertion is at the same time the negated element (i.e. the one where the sentence is not compatible with its positive counterpart) and thus in the scope of the negation. Such a topic is often felt to be in contrast with other possible topics. I shall therefore call this the 'contrastive topic case'. In this case, the information with respect to which the negated sentence differs from a affirmative counterpart is used as the topic of the

\footnotetext{
13 See Bühring 1995, and Jacobs 1997.
} 
assertion. The part following the negation particle contains only maintained information. This is deaccented and the particle itself carries the utterances main (falling) accent.

To sum up: Negation expresses that the sentence excludes the affirmative variant of the same sentence. The position of negation indicates where exactly the incompatibility problem is situated. In the 'neutral topic case', the locus of the incompatibility is situated in the part following the particle. In the 'contrastive topic case', the incompatible information has been selected as the topic of the utterance. In this case, the scope of assertion differs from the scope of the negative particle.

A very similar analysis can be applied to the additive particle auch. In this case no truth value reversal is involved. The particle expresses that instead of being incompatible, the sentence - albeit different - is indeed compatible with relevant statements in the context. As with nicht, position helps identify the locus of such differences, but instead of indicating incompatibility, auch expresses that the statements do not exclude each other but are (or should become) both true.

Crucially, we are again dealing with two different types of integration, the 'neutral topic case' and the 'contrastive topic case'. Consider the following example:

\section{Maria kommt auch beute.}

Mary comes also today.

When (21) occurs in the context of an assertion that differs from the current one in the information following the particle (i.e. beute 'today'), what is signalled is that this is where the sentences could in principle be incompatible, but are not. They are meant to be both true, so the affected information in the scope of the particle is not negated but instead added to some already established information (e.g. 'yesterday'). Here again, such an affected element can be topicalised. (21) exemplifies the 'contrastive topic case':

\section{Heute kommt Maria auch.}

Today comes Mary also.

In this case the sentence (given an appropriate intonation contour) expresses that kommen and Maria are given information whereas its topic beute is the part of the information that is different from, but compatible with what was established so far.

The idea that the affected element is used as the utterance's topic becomes particularly clear in connected discourse. The following French example shows that the element that is semantically affected by the particle (le garçon) and the focus expression, answering the interviewer's question (dans une classe spéciale) are clearly dissociated (from Benazzo, 2008).

(22) Learner Berta (L1 = Spanish, ESF Corpus, MPI)

Int: ah, elle est dans une classe spéciale

ah, she is in a special class

B: oui, la deux, marcela ${ }^{*}{ }^{*}$ ximena

yes, both, marcela and ximena

Int: hmbm dans une classe pour les non francophones (...)

$\mathrm{hmhm}$ in a special class for non francophones $(. .$.

mais le garcon, il est où?

but the boy, where is he? 


\section{B: $\quad$ le garçon (...) /elel [en *clase* spéciale $]_{\mathrm{F}}$ aussi}

the boy he-is in a special class as well.

If this analysis is correct there are, for both particles, two different integration possibilities ${ }^{14}$ in the adult native language, resulting in target sentences with similar word order but different information structure and intonation contour (the 'neutral topic case' as opposed to the 'contrastive topic case'). As will be shown in the following, however, one is more likely to occur with nicht, the other with auch.

In the 'neutral topic case' we are dealing with comments that are marked as being compatible (auch) or incompatible (nicht) with other comments about the same topic. In many discourse types (e.g. narrations) different comments can be asserted for a given topic without explicitly marking the compatibility of the resulting sentences. In (23a), the particle auch (affected information in square brackets) does not make a difference and can easily be left out (23b).
a. Maria hat Pizza gegessen. Dann hat sie auch [ein Bier getrunken]. Mary ate a pizza. Then she also drank a beer.
b. Maria hat Piqza gegessen. Dann hat sie ein Bier getrunken. Mary ate a pizza. Then she drank a beer.

This is different in the 'contrastive topic case'. To different topics occurring with the same predicate are easily interpreted as incompatible.

$$
\begin{aligned}
& \text { Gestern hat Maria Pizza gegessen. Heute hat sie Pizza gegessen. } \\
& \text { Yesterday Mary ate Pizza. Today she ate Pizza. }
\end{aligned}
$$

In this case, the particle auch signals that there is no such incompatibility, but that the given comment is indeed valid for both topics. The second claim is thus not a correction to the first one, but equally true. In this case, auch is accented and the constituents following it express maintained information and are deaccented.

\section{Gestern hat Maria Pizza gegessen. [Heute] hat sie auch Piqza gegessen.}

Yesterday Mary ate Pizza. Today she ate Pizza, too.

Different comments can be made about the same topic without raising suspicion of incompatibility. Different topics for which the same kind of comment is made do more easily evoke such concerns. In these contexts, auch marks that both sentences are indeed compatible. This is why it has a bias for occurring in the constellation labelled here 'contrastive topic case'. The 'neutral topic case', on the other hand, is the default case for nicht (as reflected in the term "sentence negation" that is used for nicht in the 'neutral topic case').

To sum up: Both integration types are possible and occur with both particles. Due to their meaning and the way they interact with the flow of information in discourse, however, the particle auch is more likely to occur in the 'contrastive topic case' in which what is used as the utterance's topic comes from within the scope of the particle, whereas nicht is frequently used in the 'neutral topic case' in which it has only scope over the elements following it.

\footnotetext{
${ }^{14}$ In fact many more, but this doesn't matter here.
} 
It is possible, that the integration of auch and nicht in early non-finite learner utterances differs along similar lines. The unequal behaviour of auch and nicht during the acquisition of finiteness might have to do with the fact the early utterances containing them - albeit looking similar at the surface - have a different information structures and that making these initial structures finite involves operations of different complexity.

\section{Same vs. different information in particle containing learner utterances}

Klein (2006) demonstrates that it is the function of finiteness to express that a non-finite initial structure is turned into an assertion that is confined to a specific topic situation. What happens if such a non-finite initial structure contains a particle like auch and nicht before the application of the assertion operator turns it into a finite sentence may depend on the way in which the particle is integrated in the initial structures.

For learner language, the question arises as to whether auch and nicht are biased in a way similar to that described for adult native language. If so, it might be possible to account for the different behaviour that utterances containing auch as opposed to nicht show during the acquisition of finiteness.

\subsection{The information structure of early learner utterances containing auch}

Let us reconsider the child language examples containing auch from section 2, repeated here as (26) and (27). Particle utterances of this type have given rise to Powers' (2001) 'flipping pivot' analysis, since auch can either precede (26) or follow (27) a content word. A different picture emerges when the distribution of maintained vs. 'different' information is taken into account. In all cases it is the 'different' information (marked by square brackets in the examples below) that is directly affected by the particle's additive meaning. Compatibility is marked between this 'different' information and other elements for which the maintained information has been claimed to be valid. These other elements can either be mentioned in an earlier utterance or present in the physical context (as in 26 and 27).

$$
\begin{array}{ll}
\begin{array}{l}
\text { Julia, } 1 ; 07 \\
\text { J. puts blocks in a box }
\end{array} & \begin{array}{l}
\text { darein } \\
\text { there-in } \\
{[\theta=\text { other block] auch darein }} \\
\text { also there-in }
\end{array} \\
\text { picking up another block } & \\
\text { Julia, 1;11 } & \begin{array}{l}
\text { einräum } \\
\text { put-in } \\
\text { Jiege] auch } \\
\text { goat also }
\end{array} \\
\text { placing goat in the box } & \text { gin a box }
\end{array}
$$$$
\text { (27) Julia, 1;11 }
$$

In these utterances, the 'different but compatible' information is at the same time the topic of the relevant utterances, i.e. the part of the information about which the child makes a claim. We are thus dealing with the 'contrastive topic case'. What does or should happen to this topic is specified in the comment part of the utterance. In the context a 
similar comment holds for a different topic. In this integration type the comment thus contains maintained information and can therefore be left implicit (as in 27).

Under an analysis that takes the distribution of different vs. given information into account, a 'flipping pivot' problem does not arise. In typical early learner utterances such as (26) and (27) auch always follows the 'different' element. Under the condition that it is present in the physical context (as in 26) reference to this new topic can be left implicit.

The way the maintained predicative information applies to the topic depends on the context. It can be a statement about a 'different' topic like in (27) or have modal/future meaning, expressing that the maintained predicative information will or should become true for a 'different' topic, like in (26).

In adult language the particle auch, when integrated in this kind of information structure, must carry the utterance's main accent. Nederstigt (2003) finds that stressed auch in exactly this kind of information structure occurs in L1 acquisition much earlier than unstressed auch. $^{15}$

In section 5. it was shown that in this integration type (the 'contrastive topic case') the items referring to the 'different' information have been topicalized and appear to the left of the particle while still behaving as if they were in its scope. One possibility of accounting for this surface word order is by way of movement of the relevant constituent. Penner et al. (2000) claim that a similar kind of movement (scrambling) already holds for the non-finite utterances occurring in early child language. A child utterance like (27) above would thus be analysed as the result of raising the subject NP riege (goat) across the particle to the specifier position of the focus particle phrase. This happens for purely syntactic, not for semantic reasons. The same kind of movement is therefore assumed to apply to negation in the 'neutral topic case'. Recall, however, that the particle nicht precedes the 'different' information in these cases such that for reasons of scope, no such movement is required (in neither child nor adult language). As we have seen, this purely syntactic account that treats both particles in a parallel way fails to predict the observed differences in development.

The alternative account by Jordens \& Dimroth (2006) is based on the observation that word order in early learner utterances in L1 or L2 is mainly based on information structure. The topic tends to occur in initial position independently of the presence of scope particles or other structure building elements across which it could have been scrambled. Given that no movement is assumed to be involved in utterances without particles, the same information structure based analysis is applied to utterances containing these or other "lexical linking words".

These linking words are seen as functional, rather than syntactic precursors of finiteness, because they specify the way in which the information in the comment of the utterance relies to its topic. As we have seen above, however, this is often the case for negation, but not for the early auch utterances which typically belong to the 'contrastive topic' type,

\footnotetext{
15 Berger et al. (2007) show in an eye tracking experiment that young children understand the difference between stressed and unstressed auch at age four. Participants reacted to utterances containing stressed auch by looking in the visual display for alternatives to the utterance's topic entity.
} 
and this is why the account equally fails to predict any differences in the further development.

auch is not used to express in which way a comment applies to a topic, it rather functions like an anaphor pointing back to an assertion involving a comment/predicate of the same type. Early uses of auch are in fact very much related to the anaphoric use of negation and assertion. Compare the following example. Instead of using yes or no in isolation as a sentence equivalent, adult L2 learners are able to reuse parts of their native interlocutors' speech as the topic of their own utterances. They combine these topics with answer particles in order to indicate if the given predicate (here: learner repairing vehicles) does or does not apply to them. ${ }^{16}$

(28) Learner Marcello (L1 = Italian; ESF-Corpus, MPI; from Becker 2005)

Int: reparieren sie selbst farbrrad oder auto?

Do you yourself repair bicicle or car?

Mo auto nein, fabrrad ja

car no, bicycle yes

The particle auch can be used in a very similar way. Part of the comment from the interviewer's utterance is taken up by the learner as the topic of his utterance, followed by the particle. The maintained information (grandpa speaking languages) is left implicit.

(29) Learner Antek (L1 = Polish, P-MoLL Corpus, MPI)

Int: hat dein grossvater polnisch gesprochen, oder nur deutsch?

Did your grandpa speak Polish or only German?

An: polnisch auch

Polish as well.

Similar examples also occur in child language. Compare the following discourse, in which mother and child discuss to whom the maintained comment information (being allowed to sing a special song) applies.

(30) Caroline 2;00 (from Nederstigt 2003)

Mother: nur die Susanne darf dis singen?

only Susanne may sing this?

Child: ja

yes

Mother: ich nicht?

not me?

Child: Mami auch

Mummy too.

Even when a (non-finite) verb is following, it typically encodes given information and auch functions as an anaphor of an earlier assertion.

(31) Caroline, 2;02 (from Nederstigt 2003)

Mami auch belfen

${ }^{16}$ See Andorno 2008 for a similar analysis of L2 Italian. 
Mummy also help

'Mummy has to help, too'

What has to be learned? Two major steps are involved when this kind of utterance is turned in to a finite sentence during further development. First, learners have to figure out that they have to mark the new assertion in addition to the one that auch anaphorically points to. ${ }^{17} \mathrm{~A}$ finite verb must be inserted in second position in order to express that an assertion is made about the topic. The topic is the topic of the finite assertion, but at the same time it is the information marked as 'different but compatible' by auch.

The second step consists of splitting up the early fixed cluster of 'contrastive topic + anaphoric assertion' in order to turn this into a finite sentence, where the particle is situated in a position following the finite verb). In such a finite sentence, assertion does not have the same scope as the particle.

The frequency of occurrence of "Topic + auch" in the early stages makes it hard to learn that the particle is not always adjacent to the topic. In L2, but sometimes also in L1, finite verbs, even auxiliaries, do not move to V2 at a time when they are systematically raised over direct objects (see the adjacency cases discussed in relation to examples (12) and (15) above). The following example (from Penner et al. 2000) illustrates the learner's difficulty:

(32) Florian 2;8 (referring to himself as Florian or Lo. Looking at a picture book.

Adult interlocutor asking what the policeman is doing)

steine bolt

stones gets

Lo auch steine $\backslash$

Lo also stones

Lo hat auch steine $\backslash$

Lo has also stones

Lo auch--.. hat auch--

Lo also- - .. has also--

Florian auch steine bolt

Florian also stones gets

Given these additional difficulties resulting from the dominant information structure in utterances containing auch, learners frequently resort to the non-finite utterance organization employed at earlier stages, even at a phase in development in which other utterances are productively marked for finiteness (compare also Winkler, this volume).

The particle auch can in principle equally occur in the 'neutral topic case' (compare example (23a) above), but it does not seem to do so in early first and second language acquisition. The reason might again be related to information structure. Whenever an utterance's comment part consists of new ('different') information, the fact that such a

\footnotetext{
${ }^{17}$ Compare Winkler (this volume) who assumes that the acquisition of the 'auch + [NP]' structure (e.g. auch Mama) helps children to understand that auch does not express an assertion. Under this assumption it remains unclear, however, why the realization of finiteness in utterances concerning auch is slower than in utterances without this particle.
} 
comment holds in addition to earlier comments that might have been made about the same topic does not have to be marked explicitly - it follows from the general rules of referential movement in discourse (Klein \& von Stutterheim 1987), at least as long as relatively simple learner discourse is concerned.

\subsection{The information structure of early learner utterances containing nicht}

The negation particle nicht can occur in the same information structure, i.e. the 'contrastive topic case', and at least in the very first stages of L2 acquisition it does so very often. As in the case of auch, there seems to be a smooth transition from anaphoric/holistic use! Instead of answering with an isolated negation particle (nein, or nicht), the learners pick up part of the native speaker's utterance and use it as a topic to be negated (see Andorno 2008). Compare the following examples.

(33) Learner Marcello (L1 = Italian; ESF-Corpus, MPI; from Becker 2005)

Int: Haben Sie eine Krankenversicherung jetat? do you have an insurance now?

Mo: Jetrt nein. now not

(34) Learner Angelina (L1 = Italian; ESF-Corpus, MPI; Dietrich \& Grommes, 1998)

Int: Und haben Sie kein Auto? and don't you have a car?

An: Mein mann babe de auto. ich niks my husband have the car. I not.

But for both, L1 and L2 the other integration type is also attested early. Here are two examples from the non-finite stage in L1 and L2 acquisition.

Julka, 2;4 (Julka Corpus, MPI) (looking for something)

julchi nich [findes]

Julchen not find-it

(36) Learner Janka (L1 = Polish; P-MoLL Corpus, MPI)

polizei nicht [guck-mal]

police not look

In these examples, nicht is followed by information in which the current utterance differs from its positive counterpart. The topic is maintained and not negated, i.e. we are dealing with the 'neutral topic case'. Making these utterances finite is less complicated, since the topic of the assertion is at the same time the part that is unaffected by nicht. The scope of both operators, assertion and negation goes to the right, and no dissociation between the information structure underlying assertion and negation is required. This might indeed be the reason why finiteness marking in this utterance type, and as a consequence, with negation overall, ${ }^{18}$ is acquired much faster than in the prototypical auch case.

\footnotetext{
18 There is a caveat insofar as most of the acquisition studies (at least in L2) have deliberately focused on the analysis of "sentence negation". An elicitation study focusing on negation in the 'contrastive topic case' might reveal that there is no head start for finiteness in this information structure.
} 
But then why is finiteness with negation even more advanced than in utterances that do not contain particles at all? Researchers who have observed the fast development of negated utterances in their L1 or L2 learner data, have made a couple of proposals.

Dietrich \& Grommes (1998: 199) assume that the syntactic differentiation of negation words (like nein, nicht, nichts, kein) promotes the construction of functional syntactic categories in negated utterances. Winkler (2006) argues that a first operator position is shared by negation and (unanalyzed finite forms of) modal verbs, i.e. items that semantically specify in which way an utterance's comment part does or should hold for the topic. She assumes that the acquisition of finiteness profits from the learners having to dissociate these forms as belonging to different categories.

Whatever the additional helping mechanisms are - it is the property of 'having scope over the comment' that negation shares with the newly acquired assertion marking operator (finiteness) and apparently this makes finiteness marking easier. This is how negation is - at least often - integrated in verb-containing learner utterances at the stage preceding the acquisition of finiteness. Early utterances containing auch, on the other hand, do not typically belong to this advantageous integration type. The following child learner utterance illustrates utterance structure at a stage in development at which nicht oscillates between its former non-finite position and the target like post-finite one, whereas there is only one position for the particle auch - adjacent to the topic constituent that at the same time represents the 'different' information and is the locus in which this utterance could be interpreted as incompatible with an earlier one, if auch didn't express compatibility.

$$
\begin{aligned}
& \text { Simone 2;0 (from Clahsen 1988) } \\
& \text { das auch nich schmeckt nich } \\
& \text { this also not taste-3sg not }
\end{aligned}
$$

\section{$7 \quad$ Summary and Discussion}

The particle auch mainly occurs in the 'contrastive topic case'. In utterances with this information structure, the acquisition of finiteness is delayed because auch functions as an anaphor of an earlier assertion in the preceding non-finite stage of development. Learners take time to figure out that they have to mark the new assertion in addition to the one that auch anaphorically points to, and that they have to split up and reanalyse the fixed cluster of 'contrastive topic + anaphoric assertion' in order to turn this into a finite sentence. In such a finite sentence, assertion does not have the same scope as the particle.

This problem does not occur with particles like nicht which are mainly integrated in the 'neutral topic case'. In this case, the 'different' information is situated in the comment part of the sentence, i.e. following the negator. Assertion and negation have the same scope. The acquisition of negation might in addition be pushed forward by the learners' need to differentiate several negation words and other operators that occur in a similar position and have scope over the information expressed in the predicate.

Early verb-containing learner utterances, be it from L1 or L2, typically show the same surface word order when they contain one of these particles: Topic - Particle - Predicate, 
often corresponding to $\mathrm{S}$ - Particle - $\mathrm{V}_{\text {(nonfin) }}$. In the majority of cases, however, those containing auch and those containing negation have different information structures, and different parts of the information is affected by the particle's scope (square brackets in Figure 4.

Figure 4: Dominant scope of auch and nicht in early learner utterances

[Topic] - auch - Predicate, or $[\mathrm{S}]$ - auch - $\mathrm{V}_{\text {(nonfin) }}$ (= 'contrastive topic case')

Topic - nicht- [Predicate], or S - nicht- $\left[\mathrm{V}_{(\text {nonfin }}\right]$ (= 'neutral topic case')

As we have seen in Section 5, it is also the case in adult native German that auch often has often scope over a constituent that is at the same time used as the utterance's topic. If we do not want to abandon the idea that the particles have scope over the elements following them, we have to assume that an additional movement has taken place, and that this movement is scope-conservative because the relevant element is situated to the left of negation in surface structure, but behaves as if it was to the right.

This assumption makes the analysis more complicated, because it means that the particle must precede the information in its scope (i.e. the information that has to be marked as 'different but compatible') on the level of some underlying initial structure. This, however, implies that some of the particle's surface positions can in principle be derived from two different initial structures. Consider a sentence like Maria ist auch gekommen (Mary has also come) and the two context dependent integration variants given in (38) and $(39)^{19}$.

(38) 'Neutral topic case':

Maria hat angerufen. Maria ist auch [gekommen].

Mary did call. Mary has also come.

corresponding initial structure: Maria auch [kommen]

Mary also [come]

(39) 'Contrastive topic case':

Peter ist dagewesen. [Maria] ist auch gekommen.

Peter was there. Mary has also come.

corresponding initial structure: auch [Maria kommen]

also [Mary come]

In the initial structure corresponding to (38) the particle is integrated in a position similar to its surface position and has scope over the following VP that contains the information marked as 'different but compatible'. In order to arrive at the surface order from the corresponding initial structure, only a finite auxiliary has to be inserted in V2.

Example (39) corresponds to the 'contrastive topic case'. In the initial structure, the particle auch has wide scope over the entire sentence including Maria. It is however possible that Maria is the only piece of information that is different from but compatible

\footnotetext{
19 As stated before, both integration types are equally possible with nicht, but the 'neutral topic case' (also called "sentence negation") is probably the default for negation.
} 
with the relevant context sentence. If in addition, Maria is chosen as the topic of the assertion, the subject NP has to be moved to initial position.

Two additional arguments speak in favour of the idea that auch is often integrated in a higher position than nicht. (i) the order of both particles when they occur in isolation in an elliptical utterance like (40)/(41) and (ii) the fact that auch, but not nicht, can occupy the position preceding the finite verb (Vorfeld) alone (42).

(40) A: Johannes war also nicht da. Und Maria?

So John was not there. And Mary?

B: Auch nicht

Also not

(41) A: Johannes war also auch da. Und Maria?

So John was also there. And Mary?

B: *Nicht auch

not also

(42) Auch ist Maria zum ersten mal gekommen.

Also has Mary for-the first time come.

* Nicht ist Maria zum ersten mal gekommen.

Klein (2007) points out that the position of negation indicates where the negated sentence is different from and incompatible with its affirmative counterpart. Very often, however, such an affirmative counterpart (the 'other' sentence, as it is called in Klein (2007)) is of no real contextual relevance. It is very natural to make a negated statement (Mary did not come) in the absence of an affirmative counterpart (specifying what Mary did instead) in the context. The particle auch differs from negation in that it expresses compatibility with another, partly different utterance. Signalling compatibility only makes sense if there is potential incompatibility, and this mainly occurs if the 'other' statement can be found in the preceding context. ${ }^{20}$ This might reinforce the learners' interpretation of auch as an anaphoric assertion operator.

\footnotetext{
${ }^{20}$ There are clear exceptions, in which the presence of auch invokes a search for a similar statement that has not been made in the context. (A: Liebst du mich auch? B: ja, dich auch.)
} 


\section{References}

Andorno, C. (2008). Entre énoncé et interaction: le role des particules d'affirmation et negation dans les lectes d'apprenants. Acquisition et Interaction en Langue Etrangère (AILE), 26, \#.

Becker, A. (2005). The semantic knowledge base for the acquisition of negation and the acquisition of finiteness. In: Hendriks, H. (ed.), The Structure of Learner Varieties. Berlin/New York, 263-314.

Benazzo, S. (2003). The interaction between verb morphology and temporal adverbs of contrast. In: Dimroth, C. \& Starren, M. (eds.), Information structure and the dynamics of language acquisition. Amsterdam, 187-210.

Benazzo, S. (2008). Marqueurs de focus, structure informationnelle et lectes d'apprenants adultes d'une L2. Actes du Colloque Mondial de Linguistique Française, Paris, 912 juillet 2008.

Berger, F., Müller, A., Höhle, B. \& Weissenborn, J. (2007). German 4-Year-Olds' Comprehension of Sentences Containing the Focus Particle auch ('also'): Evidence from Eye-Tracking. In Caunt-Nulton, H., Kulatilake, S. \& Woo, I. (Eds.), Proceedings of the 31st Annual Boston University Conference on Language Development (Vol. 1, pp. 105-116). Somerville, MA.: Cascadilla Press.

Braine, M. (1963). The ontogeny of English phrase structure: The first phase. Language, 39, 1-13.

Bühring, Daniel (1995). The 59th Street Bridge accent. On the meaning of topic and focus. Unpublished doctoral dissertation, Universität Tübingen.

Clahsen, H. (1988). Kritische Phasen der Grammatikentwicklung. Eine Untersuchung zum Negationserwerb bei Kindern und Erwachsenen. Zeitschrift für Sprachwissenschaft 7, 3-31.

Corver, Norbert \& van Riemsdijk, Henk (eds.) (2001). Semi-lexical Categories. The Function of Content Words and the Content of Function Words. Berlin/New York: de Gruyter.

Dietrich, R., \& Grommes, P. (1998). 'nicht . Reflexe seiner Bedeutung und Syntax im Zweitspracherwerb. In H. Wegener (ed.), Eine zweite Sprache lernen. Empirische Untersuchungen zum Zweitspracherwerb Tübingen: Narr, 173-202.

Dimroth, C. \& Klein, W. (1996). Fokuspartikeln in Lernervarietäten. Ein Analyserahmen und einige Beispiele. Zeitschrift für Literaturwissenschaft und Linguistik, 104, 73-114.

Dimroth, C. (1998). Indiquer la portée en allemande L2. Une etude longitudinale de l'acquisition des particules de portée. Acquisition et Interaction en Langue Etrangère, $11,11-34$.

Dimroth, C. (2002). Topics, assertions and additive words. How L2 learners get from information structure to target language syntax. Linguistics, 40, 891-923.

Dimroth, C. (2008). German at different ages: Negation and Finiteness in adult, adolescent and child learners. Language Learning, 58, 117-150.

Giuliano, P. (2003). Negation and relational predicates in French and English as second languages. In C. Dimroth \& M. Starren (eds.), Information Structure and the Dynamics of Language Acquisition. Amsterdam: Benjamins, 119-158.

Hulk, Aafke (2003). Merging scope particles: Word order variation and the acquisition of aussi and ook in a bilingual context. In Dimroth, Christine and Marianne Starren 
(eds.) Information Structure and the Dynamics of Language Acquisition. Amsterdam: Benjamins, 211-234.

Hulk, A. \& van der Linden, E. (2005). The role of illocutionary operators in the emerging grammars of bilingual children. International Journal of Bilingualism, 9, 179-203.

Jacobs, J. (1997). I-Topikalisierung. Linguistische Berichte, 168, 81-133.

Jordens, P. (2002). Finiteness in early Dutch. Linguistics, 40, 687-765.

Jordens, P. \& Dimroth, C. (2006). Finiteness in children an adults learning Dutch. In N. Gagarina \& I. Gülzow (eds.), The Acquisition of Verbs and their Grammar. Dordrecht: Springer, 173-200.

Klein, W. (2006). On finiteness. In V. van Geenhoven (ed.), Semantics in Acquisition, Dordrecht: Springer, 245-272.

Klein, W. (2007). A simple analysis of sentential negation in German. Manuscript, MaxPlanck-Institute for Psycholinguistics, Nijmegen.

Klein, W. (2008). The Topic situation. In B. Ahrenholz et al. (eds.), Empirische Forschung und Theoriebildung. Festschrift Norbert Dittmar zum 65. Geburtstag. Frankfurt am Main: Peter Lang, 287-306.

Klein, W. \& von Stutterheim, C. (1987). Quaestio und referentielle Bewegung in Erzählungen. Linguistische Berichte, 109, 163-183.

Meisel, J. (1997). The acquisition of the syntax of negation in French and German: contrasting first and second language development. Second Language Research, 13, 227-263.

Nederstigt, U. (2003). 'Auch' and 'noch' in child and adult German. Berlin/New York: de Gruyter.

Penner, Z., Tracy, R., Weissenborn, J. (2000). Where Scrambling begins: Triggering Object Scrambling at the Early Stage in German and Bernese Swiss German. In: S.M. Powers and C. Hamann (eds.), The Acquisition of Scrambling and Cliticization. Dordrecht: Kluwer, 127-164.

Perdue, C. (1996). Pre-basic varieties: The first stages of second language acquisition. Toegepaste Taalwetenschap in Artikelen 55, 135-150.

Prévost, P. \& White, L. (2000). Missing surface inflection or impairment in second language acquisition? Evidence from tense and agreement. Second Language Research 16, 103-133.

Powers, S.M. (2001). Children's semi-lexical heads. In N. Corver \& H. van Riemsdijk (eds.), Semi-lexical Categories. The Function of Content Words and the Content of Function words. Berlin/New York: de Gruyter, 97-126.

Schimke, Sarah/Verhagen, Josje/Dimroth, Christine (in press). Particules additives et finitude en néerlandais et allemande L2: une étude experimentale. Acquisition et Interaction en Language Etrangère.

Schlyter, Suzanne (2005). Adverbs and functional categories in L1 and L2 acquisition of French. In J.M. Dewaele (ed.), Focus on French as a Foreign Language: multidisciplinary approaches. Toronto: Multilingual Matters, 36-62.

Tracy, Rosemarie (2002). Growing roots. Linguistics 40, 653-686.

van Kampen, J. (2005). Language specific bootstraps for UG categories. International Journal of Bilingualism 9, 253-275.

Verhagen, J. (2005). The role of the auxiliary 'hebben' in Dutch as a second language. Zeitschrift fuer Literaturwissenschift und Linguistik (LiLi), 140, 99-127. 
Verrips, M., and J. Weissenborn. (1992). Routs to Verb Placement in Early Child German and French: The Independence of Finiteness and Agreement. In J. M. Meisel (ed.), The Acquisition of Verb Placement. Dordrecht: Kluwer Academic Publishers, 283-331.

Winkler, Stefanie (2006). Finiteness in first and second language acquisition. Annual Report; Max-Planck Institut für Psycholinguistik, Nijmegen.

Wode, H. (1977). Four early stages in the development of L1 negation. Journal of Child Language, 4, 87-102. 